• 论坛・

$$
\begin{aligned}
& \text { 哈萨克斯坦的生物多样性保护及 } \\
& \text { 中哈合作的对策建议 } \\
& \text { 吴 沝 }{ }^{1,2^{*}} \text { 郝 韵 } 1,2 \text { 张小云 }{ }^{1} \text { 王丽贤 }{ }^{1} \text { 贺晶晶 }{ }^{1,2} \text { 段光正 }{ }^{3}
\end{aligned}
$$

\begin{abstract}
摘要: 哈萨克斯坦位于欧亚大陆腹地, 地处丝绸之路经济带的重要位置。中国与哈萨克斯坦开展生物多样性保护 合作, 有助于解决地区生态环境问题和推动“一带一路”倡议的顺利实施。目前国内尚缺乏对哈萨克斯坦生物多样 性及其保护状况的了解。本文在文献的基础上通过定量和定性分析方法, 从地理环境特征、生物多样性状况、保 护成效和需求等维度对哈萨克斯坦生物多样性及其保护的总体情况进行了分析。分析结果表明, 哈萨克斯坦的生 物多样性丰富, 但也存在着较严重的丧失问题; 哈萨克斯坦政府重视生物多样性保护, 积极承担相关国际履约义 务; 在保护管理方面实行多级管理体制, 并与社会经济发展需求相结合, 取得了一定成效。
\end{abstract}

关键词: 哈萨克斯坦; 生物多样性; 保护; 中哈合作; “一带一路”; 对策建议

\title{
Biodiversity conservation of Kazakhstan and suggestions on cooperation between China and Kazakhstan
}

\author{
Miao $\mathrm{Wu}^{1,2^{*}}$, Yun Hao ${ }^{1,2}$, Xiaoyun Zhang ${ }^{1}$, Lixian Wang ${ }^{1}$, Jingjing $\mathrm{He}^{1,2}$, Guangzheng Duan ${ }^{3}$ \\ 1 Xinjiang Institute of Ecology and Geography, Chinese Academy of Sciences, Urumqi 830011 \\ 2 Research Center for Ecology and Environment of Central Asia, Chinese Academy of Sciences, Urumqi 830011 \\ 3 Foreign Environmental Cooperation Center, Ministry of Ecology and Environment (China Center for SCO \\ Environmental Cooperation), Beijing 100035
}

\begin{abstract}
Kazakhstan is located in the hinterlands of Eurasia and is an important part of the Silk Road Economic Belt. Cooperation between China and Kazakhstan that is focused on the conservation of biodiversity will help solve regional ecological and environmental problems and promote the smooth implementation of the "One Belt, One Road" initiative. China still lacks a basic understanding of Kazakhstan's biodiversity and the conservation status of different organisms. Using both quantitative and qualitative analyses, we used geographic environmental characteristics, biodiversity status, and different levels of conservation effectiveness to understand the degree of biodiversity present in Kazakhstan. We found that Kazakhstan is rich in biodiversity, but is also at serious risk of losing biodiversity. Kazakhstan's government emphasizes the importance in protecting biodiversity and is active in complying with international obligations. The government has been able to combine the social and economic needs of the nation in implementing a multi-level management system that has been achieved certain results.
\end{abstract}

Key words: Kazakhstan; biodiversity; conservation; China-Kazakhstan cooperation; One Belt One Road; Countermeasure and Suggestion

近年来在全球气候变化和“一带一路”背景下的 中亚生态环境状况及其保护问题引起了国内学术
界的关注, 学者们分别对中亚干旱区的生态环境状 况(周可法等, 2006; 胡汝骥等, 2014)、哈萨克斯坦 
与新疆的生物多样性差异(张小云等, 2010)、塔吉克 斯坦的动物多样性特点等方面进行了研究(李叶等, 2013), 并对推进“一带一路”过程中有关生物多样 性保护等问题进行了探讨(孟宏虎和高晓阳, 2019)。 但总体而言, 有关哈萨克斯坦生物多样性现状及其 保护管理机制、体系的研究仍然较为缺乏。

哈萨克斯坦是中亚国土面积最大和世界第九 大内陆国家。哈萨克斯坦还是“西方-西伯利亚-阿 富汗” 和 “中亚-印度”迁徙鸟的两大重要通道以及 121 个具有全球意义的鸟类栖息地。生物多样性是 生态环境变化的重要指示, 哈萨克斯坦与相邻的中 国新疆共处于同一地理单元, 通过对其生物多样性 构成、变化和保护措施等方面的研究, 可为了解该 区域生物多样性的演化趋势提供借鉴, 从而为在 “一带一路”倡议下开展双边环保合作和制订区域生 态环境保护政策提供科学支撑。

\section{1 概况}

\section{1 地理概况}

哈萨克斯坦总面积为 272.5 万 $\mathrm{km}^{2}$, 人口近 1,828 万(World Bank，2019)。其国土位于欧亚大陆腹地， 东部与中国新疆接壤, 远离海洋, 为典型的大陆性 气候。

\section{2 自然环境特征}

哈萨克斯坦由于地域广阔，局部气候具有明显 的差异性。南部为暖温带荒漠区，中部为温带干旱一 半干旱区, 北部为寒温带半干旱区。景观的自然地 带性明显，主要有沙漠、荒漠草原、低山草原、山 地森林和高山草甸等, 其中干旱和半湿润地带约占 国土面积的 $75 \%$ ，森林覆盖率4.61\%。地貌属典型的 山盆结构, 北部是西阿尔泰山和半干旱森林草原区, 南部是西天山或荒漠半荒漠区，中部为平原，由荒 漠草原和荒漠构成。

\section{生物多样性概况}

\section{1 生态系统多样性现状}

哈萨克斯坦的自然生态系统多样性较为丰富 (Крайнюк et al, 2005), 主要包括森林草原、草原、 荒漠、山地和水-湿地及海洋生态系统(表1)。

其中山地生态系统、水-湿地和海洋生态系统 与中国的新疆有着密切联系, 有些属于同一生态系 统, 如哈萨克斯坦东南部的天山山地、东部的塔尔 巴合台山地、伊犁河和额尔齐斯河的水-湿地生态 系统等。同时由于咸海干涸对生态环境造成的负面 影响已不仅局限于沿岸国家而且波及包括中国西 部在内的域外区域，使咸海生态问题成为区域乃至

表1 哈萨克斯坦自然生态系统多样性概况

Table 1 The situation of ecosystem diversity in Kazakhstan

\begin{tabular}{|c|c|c|c|c|}
\hline $\begin{array}{l}\text { 生态系统类型 } \\
\text { Ecosystem type }\end{array}$ & $\begin{array}{l}\text { 空间分布 } \\
\text { Spatial distribution }\end{array}$ & $\begin{array}{l}\text { 主要植物类群 } \\
\text { Main plants }\end{array}$ & $\begin{array}{l}\text { 主要动物类群 } \\
\text { Main animals }\end{array}$ & $\begin{array}{l}\text { 景观变化特征 } \\
\text { Landscape change }\end{array}$ \\
\hline $\begin{array}{l}\text { 森林草原 } \\
\text { Forest steppe }\end{array}$ & $\begin{array}{l}\text { 哈萨克斯坦北部 }\left(70 \times 10^{4}\right. \\
\text { ha) } \\
\text { Northern Kazakhstan }(70 \times \\
\left.10^{4} \text { ha }\right)\end{array}$ & $\begin{array}{l}\text { 森林、草本植物 } \\
\text { Forests, herbs }\end{array}$ & $\begin{array}{l}\text { 啮齿类、飞禽 } \\
\text { Rodents, birds }\end{array}$ & $\begin{array}{l}\text { 变化不大 } \\
\text { Slightly changed }\end{array}$ \\
\hline $\begin{array}{l}\text { 草原 } \\
\text { Steppe }\end{array}$ & $\begin{array}{l}48^{\circ}-52^{\circ} \mathrm{N} \text { 之间 } \\
\left(1.1 \times 10^{8} \mathrm{ha}\right) \\
\text { Between } 48^{\circ}-52^{\circ} \mathrm{N}(1.1 \\
\left.\times 10^{8} \mathrm{ha}\right)\end{array}$ & $\begin{array}{l}\text { 早生禾本植物、灌木 } \\
\text { Xerophytes, shrubs }\end{array}$ & $\begin{array}{l}\text { 草原植食鸟类 } \\
\text { Grassland } \\
\text { herbivorous birds }\end{array}$ & $\begin{array}{l}\text { 农业开层强度大、原生植被破 } \\
\text { 坏严重 } \\
\text { High intensity of agricultural } \\
\text { reclamation, original vegetation } \\
\text { were seriously damaged }\end{array}$ \\
\hline $\begin{array}{l}\text { 荒漠 } \\
\text { Desert }\end{array}$ & $\begin{array}{l}\text { 从里海沿岸至塔尔巴哈台山 } \\
\text { 麓 }\left(1.2 \times 10^{8} \text { ha }\right) \\
\text { From the coast of the Caspian } \\
\text { Sea to the foothills of Talb- } \\
\text { ahatai }\left(1.2 \times 10^{8} \text { ha }\right)\end{array}$ & $\begin{array}{l}\text { 荒漠和盐生植物 } \\
\text { Eremophytes and halophytes }\end{array}$ & $\begin{array}{l}\text { 啮齿类及其天敌、 } \\
\text { 爬行类、鸟类 } \\
\text { Rodents and their } \\
\text { natural enemies, rep- } \\
\text { tiles, birds }\end{array}$ & $\begin{array}{l}\text { 荒漠化威胁 } \\
\text { Threat of desertification }\end{array}$ \\
\hline $\begin{array}{l}\text { 山地 } \\
\text { Mountain land }\end{array}$ & $\begin{array}{l}\text { 东部、南部的山地 }\left(0.2 \times 10^{8}\right. \\
\text { ha) } \\
\text { Eastern and southern moun- } \\
\text { tains }\left(0.2 \times 10^{8} \mathrm{ha}\right)\end{array}$ & $\begin{array}{l}\text { 乔灌草植物大量分布, 植被垂 } \\
\text { 直变化显著 } \\
\text { A large number of trees, shrubs, } \\
\text { herbs, and significant vertical } \\
\text { changes in vegetation }\end{array}$ & $\begin{array}{l}\text { 哺乳动物丰富 } \\
\text { Rich in mammals }\end{array}$ & $\begin{array}{l}\text { 西阿尔泰山脉的西伯利亚动物 } \\
\text { 区系数量减少 } \\
\text { Decreased Siberian fauna in } \\
\text { western Altai Mountain }\end{array}$ \\
\hline $\begin{array}{l}\text { 水-湿地和海洋 } \\
\text { Water-wetland and ocean }\end{array}$ & $\begin{array}{l}\text { 河流、湖泊(含里海)等 } \\
\text { Rivers, lakes (including } \\
\text { Caspian Sea) }\end{array}$ & $\begin{array}{l}\text { 山核桃、苦草及海草等 } \\
\text { Pecan, eel grass, seaweed, etc. }\end{array}$ & $\begin{array}{l}\text { 水鸟等 } \\
\text { waterfowls }\end{array}$ & $\begin{array}{l}\text { 三角洲盐渍化、咸海干涸等 } \\
\text { Salinization of delta, drying up } \\
\text { of the Aral Sea }\end{array}$ \\
\hline
\end{tabular}


世界性共同关注的焦点。对生态系统多样性的保护 和发展已不能仅仅依靠单一国家解决, 必须通过利 益相关方的双边和多边国际合作才能提升治理效 果, 这为今后中国与哈萨克斯坦在该领域开展互惠 合作提供了契机。

\section{2 物种多样性现状}

哈萨克斯坦多样化的地形地貌和气候特征决 定了丰富的物种多样性, 是中亚国家中最重要的生 物多样性分布区。其物种丰富度从西部草原区向东 部沙漠区, 北部的阿尔泰山至西南部的西天山和卡 拉套山呈逐渐增加趋势。

目前, 在已记录的植物种类中, 有约 6,000 种高 等植物、5,000种菌类、485种苔藓、2,000余种藻类 等(Паршина et al, 2012)。在高等植物中包含了多种 药用、饲料、经济、食用和观赏类植物, 其中药用 植物大多分布在外伊犁阿拉套山、昆格山、准噶尔 -阿拉套山、吉尔吉斯山脉、阿尔泰山脉等山区。

已探明的野生动物中共有 890 种脊椎动物(表2), 分属5纲50目129科, 其中哺乳类178种、禽(鸟)类500 种、爬行类49种、两栖类13种、鱼类147种、无领 动物 3 种; 无脊椎动物超过 10 万种, 其中昆虫约占 $50 \%$ 。已被列入哈萨克斯坦红皮书名录的有 128 种脊 椎动物和96种无脊椎动物, 其中包括85种昆虫、 1 种甲壳类动物、 6 种软体动物和 2 种蠕虫 $(\mathrm{MCX} \mathrm{PK}$, 2018)。

哈萨克斯坦还拥有独特的具有全球意义的农 业遗传资源, 其中包括决定了 24 种农作物潜力的 226种野生近缘植物。目前, 得到世界广泛认可的有 野苹果 (Malus sieversii) 和普通杏 (Armeniaca vulgaris), 其中前者的基因几乎存在于现有全部现 代商业苹果品种之中。阿月浑子(Pistacia vera)、巴 旦杏(Amygdalus communis)和葡萄(Vitis vinifera)具
有良好的耐寒基因; 酷栗 (Ribes spp.) 和醋栗 (Glossularia spp.)对弥补哈萨克斯坦浆果产量的不 足具有现实意义。此外，哈萨克斯坦还有多种蔬菜 植物 (胡萝卜Daucus carota、马齿苋Portulaca oleracea、芦笋Asparagus spp.、葱Allium spp.)、30 余种观赏植物(郁金香Tulipa spp.)、经济植物(亚麻 Linum spp.、红花Carthamus spp.)和饲料植物(苜宿 Medicago spp.)等具有全球性遗传资源保护价值的 植物物种 (Министерство окружающей средыи водных ресурсов Республики Казахстан, 2014)。

\section{3 生物多样性变化状况}

在物种多样性方面，由于人类活动和动物栖息 地环境的变化、捕杀(狼和烸)数量的增多以及偷猎 等, 哈萨克斯坦目前的主要狩猎动物物种数呈减少 趋势，有些物种减少了 $30 \%-50 \%$ 。该国 489种鸟类 中，有140多种分布于鸟类狩猎场，43种为可被猎取 物种。在35种食肉鸟中, 有半数在20世纪50-60年代 就已成为珍稀或灭绝物种(张小云等, 2010)。根据 哈 萨克斯坦《第六期国家生物多样性报告》，有224 种动物被列为国家级濒危物种, 有 110 种被纳入《濒 危野生动植物物种国际贸易公约》附录(CITES) (MCX PK, 2018)。一些国际组织将生物多样性面临 的威胁列为该国最严重的 5 个生态问题之一 (Региональный экологический центр Центральной Азии, 2009)。哈萨克斯坦植物中的松柏和被子植物 是丧失情况较严重的物种, 动物中的两栖类、爬行 类和哺乳类的状况不容乐观(图1); 在2009-2016年 间，被列入珍稀濒危的哺乳动物和鸟类在2010年出 现了较大增长, 而鱼类的情况保持稳定 (图 2) (ЮНЕП, 2003; НИЦ МКУР, 2007; ИАЦООС, 2017)。

在遗传多样性方面, 尽管哈萨克斯坦拥有较丰

表2 哈萨克斯坦物种多样性概况

Table 2 The situation of biodiversity in Kazakhstan

\begin{tabular}{ll||ll}
\hline 植物多样性 Plant diversity & 种数 Species no. & 动物多样性 Animal diversity & 种数 Species no. \\
\hline 高等植物 Higher plants & 5,754 & 脊椎动物 Vertebrate & 890 \\
低等植物 Lower plants & 8,000 & 无脊椎动物 Invertebrate & 100,000 \\
珍稀濒危植物 Rare and endangered plants & $600\left(404^{*}\right)$ & 珍稀濒危动物 Rare and endangered animals & $224\left(128^{* *}\right)$ \\
外来种 Exotic species & 500 & 外来种 Exotic species & - \\
总计 Total & $>13,000$ & 总计 Total & $>100,000$ \\
\hline
\end{tabular}

* 指被列入哈萨克斯坦红皮书; ** 指脊椎动物 * Listed in the Red Book of Kazakhstan; ** Vertebrate 


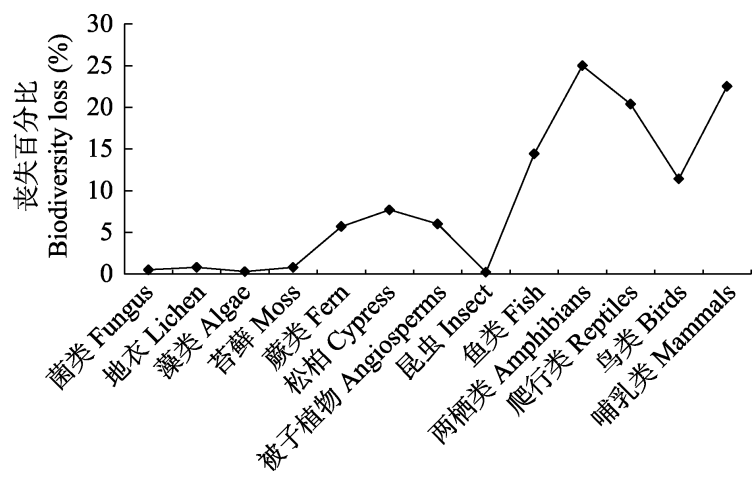

图1 哈萨克斯坦不同生物类群的物种丧失百分比(НИЦ МКУР, 2007)

Fig. 1 Percentage of species loss in Kazakhstan (НИЦ МКУР, 2007)

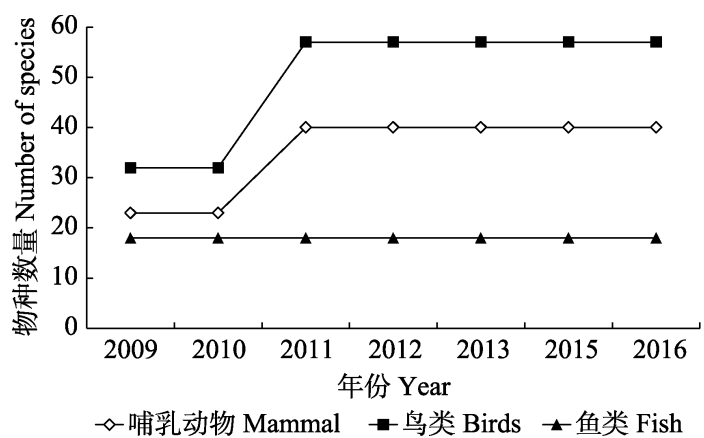

图2 2009-2016年哈萨克斯坦部分珍稀濒危动物的物种数 量变化

Fig. 2 The changes in rare and endangered species of some animal species in Kazakhstan from 2009 to 2016
富的农业遗传多样性资源，但依然有不少野生近缘 品种正在遭受遗传侵蚀的威胁(Алимгазинова et al, 2012)。例如哈萨克斯坦的小麦、大麦和燕麦的野生 近缘植物至今仍被用来作为饲草，这将导致这些物 种的灭绝。

在生态系统方面，由于大规模的垦荒使全国范 围的土地质量遭受影响，国土面积的70\%（主要是 草原带)存在不同程度的荒漠化和其他退化现象, 使不少原生植物濒临灭绝。草原带(北部、中部和西 部)的动物栖息地也因此受到破坏，山地生态系统 中的天山山麓和低山山区的生物多样性保护面临 着更为复杂的状况。由于滥砍盗伐、泥石流和林火 等因素，森林生态系统也面临着严峻的挑战。水生 生态系统中的一些三角洲(如咸海)出现严重的盐渍 化现象。

\section{3 生物多样性保护和需求}

\section{1 生物多样性保护管理体系}

哈萨克斯坦在生物多样性保护管理方面由中 央立法和执行机构与地方执行机构共同发挥管理 职能，同时还有专业组织和国际组织的参与。综合 哈萨克斯坦实施的几部与生物多样性保护相关的 主要法律，总结出哈萨克斯坦实施生物多样性保护 管理机制的大致框架(图3)。

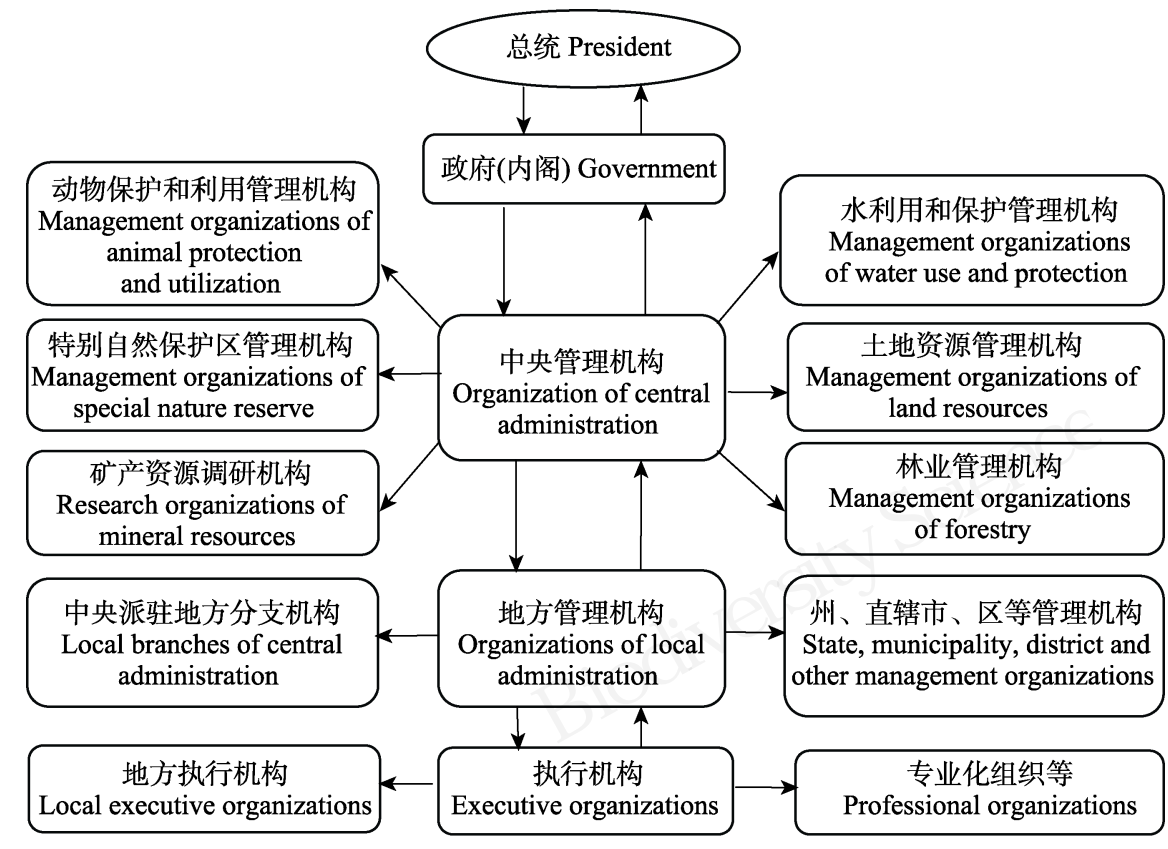

图3 哈萨克斯坦生物多样性保护管理体系

Fig. 3 The system of Kazakhstan's biodiversity conservation management 
在哈萨克斯坦生物多样性保护管理体系中, 总 统作为最高决策者, 负责签署与包括生物多样性保 护在内的生态环境领域相关的国家法律法规和国 际协议、公约、议定书等文件，使之产生效力。

哈萨克斯坦政府(内阁)负责主要方针与国家政 策的制定并保障实施, 并向总统提交相关生态保护 领域的政策、法规草案; 批准下级机构提交的珍稀 濒危物种目录、落实政府签署的相关国际协议并开 展国际合作等。

中央层级国家管理机构包含了若干专业性的 机构(如生态、地质和自然资源部、农业部、教育和 科学部、工业和基础设施发展部), 负责实施该领域 的国家政策，协调部门间的关系，制定、实施和向 政府提交生物多样性保护领域的法律规范、标准、 保护物种清单, 组织开展相关科学研究工作, 对下 级机构的相关工作进行监督检查、开展国家生态监 管等。

地方层级管理机构负责批准职权范围内的计 划、专项指标、行政管理规范等, 听取地方执行机 构和其他相关组织的生态状况汇报, 执行国家颁布 的相关法律法规等。地方执行机构负责执行国家、 地方相关政策法规，制定并向地方管理机构提交有 关生态保护规范、标准, 与其他相关方共同制定并 向上级管理机构提交有关税费标准等 (Министерство энергетики Республики Казахстан, 2015)。

哈萨克斯坦生态、地质和自然资源部(原能源部)
是全权负责生物多样性保护和自然资源合理利用 管理的国家职能机关，其职责包括实施国家层面签 署的生物多样性领域的国际合作协议。其余部委负 责各职权范围内与生物多样性保护相关的业务。

\section{2 生物多样性保护状况}

\subsection{1 红皮书收录物种情况}

1978年1月，哈萨克斯坦出版了前苏联的第一 部红皮书, 书中收录了 87 种(亚种)脊椎动物, 分为 稀有种和濒危物种两个等级。1996年起，哈萨克斯 坦开始出版其在苏联解体后的第一部红皮书(总第 三部), 收录了 125 种脊椎动物。该红皮书第一部分 得到了美国雪佛龙公司的资助(Банк рефератов, 2016)。目前，哈萨克斯坦红皮书中计有404种植物， 其中33种为极度濒危物种、25种濒危物种、21种脆 弱物种(张小云等, 2010)。

\subsection{2 就/迁地保护}

在就地保护方面，哈萨克斯坦主要通过建设国 家自然综合保护区、国家自然公园、自然保留地、 禁伐禁猎区等多种类型、等级的特别自然保护区等 发挥保护功能。哈萨克斯坦早在1926年就建立了其 第一个自然综合保护区“阿克苏-扎巴戈利”，也是 中亚地区的第一个自然保护区，用于保护和研究当 地的自然环境与发展进程、典型生态系统、动植物 多样性及其遗传资源等(Садвакасова AT, 2012)。

目前哈萨克斯坦全国的特别自然保护区面积 已从 1990 年的 13.83 万 $\mathrm{km}^{2}$ 增加到 2017 年的 24.43 万 $\mathrm{km}^{2}$ ，保护区类别也从比较单一的自然综合保护区

表3 2013-2017年哈萨克斯坦各类特别自然保护区面积分布

Table 3 The areas of special nature reserves in Kazakhstan between 2013 and 2017

\begin{tabular}{|c|c|c|c|c|c|}
\hline 类别 Category & 2013 & 2014 & 2015 & 2016 & 2017 \\
\hline 特别自然保护区总面积 Total area of special nature reserves $\left(\times 10^{3}\right.$ ha) & $23,873.2$ & $23,873.2$ & $24,018.8$ & $24,428.7$ & $24,428.7$ \\
\hline \multicolumn{6}{|l|}{ 各类保护区所占比例 Proportion of various types of protected areas (\%) } \\
\hline 综合自然保护区(严控的自然保留地和野生环境) & 6.7 & 6.7 & 6.7 & 6.6 & 6.6 \\
\hline \multicolumn{6}{|l|}{$\begin{array}{l}\text { Comprehensive nature reserves (strictly controlled natural reserves and } \\
\text { natural environments) (\%) }\end{array}$} \\
\hline 自然保留地 Natural reserve (\%) & 9.7 & 9.7 & 9.6 & 11.1 & 11.1 \\
\hline 国家公园 National park (\%) & 10 & 10 & 10.5 & 10.3 & 10.3 \\
\hline 植物园 Botanical garden (\%) & 0.002 & 0.002 & 0.002 & 0.002 & 0.002 \\
\hline 地区级自然公园 Regional natural park (\%) & 0.8 & 0.8 & 0.8 & 0.8 & 0.8 \\
\hline 自然纪念地 Natural monument (\%) & 0.002 & 0.002 & 0.002 & 0.002 & 0.002 \\
\hline 物种或栖息地管理区(禁伐禁猎区等) & 72.8 & 72.8 & 72.4 & 71.2 & 71.2 \\
\hline $\begin{array}{l}\text { Species or habitat management area (zone forbidden to tree cutting } \\
\text { and hunting) (\%) }\end{array}$ & & & & & \\
\hline
\end{tabular}


扩大到国家自然公园、自然保留地、禁伐禁猎区等 多种类型(表3) (Айдапкелов, 2018)。根据《第六期 国家生物多样性报告》的规划, 到2050年全国各类 特别自然保护区的面积将达到 35.6 万 $\mathrm{km}^{2}$, 占国土 面积的13\%。

迁地保护多用于哈萨克斯坦相关部委(如教育 科学部和农业部)所属的研究机构、植物园, 以及其 他部门和地方政府所属的动物园、苗圃等。植物园 在植物生物多样性保护方面具有十分重要的意义。 目前哈萨克斯坦全国共有5座较大型的植物园(享有 特别保护区地位), 分别位于不同的自然区。其中最 具有代表性的是哈萨克斯坦植物与植物引种研究 所的主植物园, 收集有超过 7,000种的草本植物和 895 种木本植物 (来自 49科 129 属) (Айдапкелов, 2018)。

但由于资金缺乏和专业人才流失，哈萨克斯坦 的迁地保护区发展停滞, 一些地方植物园甚至丧失 了特别保护区地位(如卡拉干达植物园和铁米尔套 植物园), 这对珍稀物种的保护造成了不利影响。

\subsection{3 加入国际公约情况及相应政策措施}

1992年, 独立后不久的哈萨克斯坦就正式在巴 西里约热内卢签署了《生物多样性公约》(1994年正 式批准) (Данченко \& Кабанова, 2007)。之后又陆续 加入了《跨境河流和国际湖泊保护与利用公约》 (1992年)、《防治荒漠化公约》(1997年)、《濒危野生 动植物国际贸易公约》(1999年)、《作为水鸟栖息地 的跨国水-湿地公约》(2005年)、《里海海洋环境保 护框架公约》(2003年)、《保护迁徙野生动物公约》 (2005年)等。哈萨克斯坦2008年6月17日颁布的《关 于批准应对生物多样性公约的卡塔赫纳生物安全 议定书》, 标志着哈萨克斯坦正式履行卡塔赫纳生 物安全议定书的责任和义务 (Государственный Фонд экологической информации, 2019)。上述加入 与生物多样性保护相关的国际公约的行为, 表明哈 萨克斯坦希望借此促进以国际化的标准开展生物 多样性保护工作，并得到国际社会的帮助。

为了切实落实和履行各项公约所赋予的责任 与义务, 哈萨克斯坦出台了一系列法律法规和政策 措施:

在法律层面, 为了确保生物多样性公约的顺利 实施以及相应措施的权威性和严肃性，哈萨克斯坦 相继出台了《环境法》和《环境保护法》(1997年)、
《特别自然保护区法》(1997年)、《动物保护、再生 和利用法》(1993年)、《森林法》(2003年修订)、《环 境影响评估法》(1999年)、《水法》(2003年)、《生态 法》(2007年)、《行政犯罪法》(2001年)、《刑法》(1997 年)及其他相关法律法规(Министерство окружающей средыи водных ресурсов Республики Казахстан, 2014), 这些法律文件从不同角度对保护和利 用生物多样性的行为进行了规范。

在国家政策措施方面，相继出台了《国家环境 保护行动计划》《生物多样性保护及可持续利用国 家战略和行动计划》《遗传植物资源中长期发展战 略》以及其他具体的部门和地方与生物多样性保护 相关的文件(Министерство окружающей средыи водных ресурсов Республики Казахстан, 2014)。

此外, 根据《生物多样性公约》的责任和义务, 哈萨克斯坦从1999年起在联合国环境规划署和 全球环境基金等国际组织的支持下开始定期发布 国家生物多样性报告，截至2018年已发布了6期。

“哈萨克斯坦-2050”战略和向“绿色经济”过渡 构想是哈萨克斯坦中远期战略发展方针 (Official Site of the President of the Republic of Kazakhstan \& Greenkaz, 2019)。前者提出到2050年要大幅提升国 民福祉和社会经济发展水平，进入世界最发达30国 之列; 后者提出要改变传统经济结构和发展模式, 走环境友好型的绿色可持续发展之路, 优先任务是 提高资源(水、土地和生物等资源)的利用和管理效 率、实现基础设施的现代化改造和建设、通过减轻 环境压力来提升人民生活水平和环境质量以及提 高包括水和粮食等在内的国家安全。这两项战略方 针及其所规划的目标也已成为哈萨克斯坦今后各 项生物多样性保护措施的基础性纲领文件。

\section{3 生物多样性保护需求}

由于哈萨克斯市场机制尚未完全建立，社会经 济发展虽然取得一定成就, 但除了能源领域外的农 业、科技和教育等方面依然有待发展。其在生物多 样性保护方面的首要任务就是在国际社会的帮助 下摸清生物多样性本底情况。即首先对现有珍稀濒 危物种的全面清查和保护; 其次, 在保护的基础上 研究探讨对重点区域生物多样性的恢复、更新和合 理利用, 如北咸海地区、里海沿岸和其他发生大面 积盐渍化、荒漠化的灌溉区和草场等分布区; 第三， 在可持续开发的基础上，挖掘生物资源对提高人民 
生活福祉、改善生态环境和提高国家在水、粮食和 生物资源安全方面的潜力。

因此, 哈萨克斯坦在生物多样性保护领域的需 求是全方位的, 涵盖从生物多样性保护制度、保护 方法、资金筹措、保护区网络建设、科学研究、人 才培养等各领域。目前主要在以下几个方面需要扩 大和加强与国际社会的合作：(1)建立具有代表性且 符合国际标准的可促进生物多样性保护的国家生 态(监测、管理)网络，并纳入国际生态保护相关体系， 如“联合国教科文组织世界自然与文化遗产名录”、 “人与生物圈”计划等; (2)保护和恢复珍稀濒危物种 的先进方法和技术并对国内生物多样性状况进行 系统性清查; (3)保障生物多样性保护、再生产和可 持续利用的法律法规、标准规范以及国家和地区层 面生物多样性保护战略规划、纲要的制定与落实; (4) 合理地综合利用多样性的生物资源; (5)研究将生态 系统方法应用于生态系统管理; (6)对农业生物多样 性的保护(通过对退化土地、撂荒地的恢复以及有机 耕作等方法); (7)生物多样性保护领域的人才培养 以及多渠道的资金筹措等。

\section{4 小结}

\section{1 生物多样性丰富, 但存在较严重的丧失问题}

哈萨克斯坦虽然拥有丰富、多样的生物物种资 源和遗传资源，但由于自然和人为因素的共同影响， 哈萨克斯坦的动植物物种存在较严重的丧失情况, 其中最严重的是两栖类和爬行类, 哺乳动物物种的 情况也不乐观; 植物中松柏和被子植物的丧失情况 需引起严重关切。

\section{2 重视生物多样性保护, 积极承担相关国际履 约义务}

哈萨克斯坦是中亚地区最早建立自然保护区 和发布红皮书的国家之一。独立伊始即参加了包括 联合国《生物多样性公约》在内的多种国际公约和 保护议定书，并与联合国、欧盟、全球生态基金等 国际组织积极开展合作, 彰显了哈萨克斯坦在该领 域的开放与合作立场。

\section{3 实施生物多样性多级管理, 保护成效日渐凸显}

在生物多样性保护与管理方面, 哈萨克斯坦采 用了中央和地方的自上而下多级管理机制, 在具体 职能方面, 以生态、地质和自然资源部为主要部门,
农业部、教育和科学部以及工业和基础设施发展部 负责各自专业领域与生物多样性保护相关的职能 的多部门参与的形式开展具体工作, 保护成效逐年 显现，为区域生物多样性保护作出了示范。

\section{4 生物多样性保护与社会经济发展相结合, 体} 现了区域特色

由于哈萨克斯坦的社会经济发展目前仍处于 转型阶段, 地区之间和行业之间的差距依然十分显 著，为了实现到2050年进入世界最发达国家之列的 战略目标, 哈萨克斯坦生物多样性保护工作重点突 出服务于国家战略的需求，将生物多样性保护工作 与当地的社会经济发展、生态环境稳定保持以及居 民的健康有机结合，体现了良好的区域特色。但是， 由于国家独立时间较短，保护资金短缺、人才不足 仍是制约生物多样性保护的瓶颈。

\section{中哈生物多样性保护合作的几点思考}

5.1 推进中哈生物多样性保护合作, 助力“一带一 路”倡议

“一带一路”倡议提出已逾5年，受到了多数沿 线国家的积极响应。但仍有一些国家不断在各方面 掣肘这一倡议的推进，生态环境领域就是其中之 一。如一些国外专家和媒体就对“一带一路”倡议对 中亚水安全的影响表示了关注(吴沝编译, 2018; 王 丽贤编译, 2019)。

人类活动、外来种入侵和气候变化等对中亚地 区大国哈萨克斯坦的生态系统带来巨大威胁，也是 造成生物多样性丧失的主要因素，但其中首要的是 人类活动, 这一点在社会经济尚处于发展中阶段且 地处生态脆弱的干旱区的哈萨克斯坦尤为突出。而 “一带一路”建设的重点内容之一就是基础设施，如 高速公路、高速铁路、油气管线的建设等。这些建 设活动如果未经详细的环境影响评价、生态环境保 护配套措施和积极与当地社区沟通，极易引起当地 民众的反对，从而对“一带一路”倡议的推动造成负 面影响。因此，应重视对哈萨克斯坦等“一带一路” 沿线国家生物多样性的研究并通过合作提出有效 的保护对策。

\section{2 满足中哈生物多样性保护合作需求}

第十五次生物多样性缔约方大会将在中国举 办，如何达成“2020后生物多样性框架”并使之得到 有效落实, 了解各缔约国的生物多样性保护诉求和 
关切点是不可或缺的一环。

与哈萨克斯坦乃至其他“一带一路”国家开展生 物多样性保护合作, 要以共赢为原则, 找到合作契 合点。要充分了解哈萨克斯坦生物多样性的现状、 特点以及生物多样性保护工作的管理机制、国家政 策和主要关注点, 做到有的放矢, 加强针对性, 以 提高合作效率。

当前中哈在该领域的合作应以双边跨境区域 生物多样性调查、珍稀和濒危物种的保护与恢复、 生物多样性资源的保护和可持续综合利用、专业人 才培养, 以及解决包括“咸海危机”在内的区域性重 大生态问题等为抓手，逐步深化和扩大。

在具体合作方式上可采取: (1)建立生物多样性 长效保护体系，包括监测、评估与预警体系，基于 社区保护的能力框架与管理体系, 全国性的宣传保 育体系等; (2)制定相应的联合保护政策和行动计划, 建立跨境自然保护区，实施生物多样性跨区域联合 保护; (3)建立中哈生物多样性长效保护机制, 开展 共同监测和联合评估，推进两国的生物多样性保护 合作进程等。

\section{3 抓住机遇做好顶层设计}

2018年6月, 在中国青岛举行的上海合作组织 成员国元首理事会上发表了《上海合作组织成员国 元首理事会青岛宣言》。《宣言》指出, “成员国基于 维护上合组织地区生态平衡、恢复生物多样性的重 要性, 为居民生活和可持续发展创造良好条件, 造 福子孙后代，通过了《上合组织成员国环保合作构 想》”。这标志着包括生物多样性保护在内的环保 合作被纳入了上海合作组织框架内区域合作的重 要领域(中国-上海合作组织环境保护中心, 2018)。

包括哈萨克斯坦在内的上合组织成员国均属 于“一带一路”沿线国家, 在国家层面达成环保合作 共识,为各国今后在该领域的合作提供了政策保障。 我国的政府部门、科研机构和企业应积极行动起来, 加紧做好顶层设计并依此制订战略规划和具体行 动计划, 落实高层达成的环保合作共识。在上合组 织框架内顺利开展包括生物多样性保护在内的环 保合作，也可为与“一带一路”沿线其他国家开展类 似的合作提供范例。

\section{4 推进跨地区合作和共同保护}

世界银行、欧洲复兴开发银行、亚洲开发银行、 全球生态基金等国际组织以及联合国所属的环境
规划署等机构较早就与哈萨克斯坦在生态环境领 域开展合作, 此外哈萨克斯坦与亚太经济合作组织 经社委员会、欧盟委员会、欧洲环境局、北约、世 界自然保护联盟、世界自然基金会、世界保护监测 中心、欧洲自然保护中心合作也非常密切。这些机 构在生态政策制定、环保战略规划、项目设计和制 度建设、人才培养等方面为哈萨克斯坦在生态领域 的国际化建设方面给予了很大帮助，也积累了丰富 的经验。

此外, 基于解决区域性生态环境问题而成立的 拯救咸海国际基金会、中亚区域生态中心等地区性 组织在国际组织的支持下，在改善地区生态环境方 面也做了大量工作。

中国在与包括哈萨克斯坦在内的中亚国家开 展生物多样性保护合作时，应加强与这些机构的联 系，利用他们丰富的国际合作经验、技术和资金， 推进该领域工作的开展。

\section{参考文献}

Aidapkelov NC (2018) Environmental Protection and Sustainable Development in Kazakhstan, Ministry of Economy of Kazakhstan, Astana, pp. 187-190. (in Russian) [Айдапкелов НС (2018) Охрана Окружающей Среды и Устойчивое Развитие Казахстана, Министерство Национальной Экономики Республики Казахстан, Астана, pp. 187-190.]

Alymagazynova BSH, Ehimbekova MA (2012) Kazakhstan plant genetic resources: Current situation and prospects. Vavilov Journal of Genetics and Breeding, 3, 648-651. (in Russian) [Алимагазинова БШ, Есимбекова МА (2012) Генетические ресурсы растений Казахстана: Состояние и переспективы. Вавиловский журнал генетики и селекции, 3, 648-651.]

Center of Information Analysis of Environmental Protection (2017) State Report on the Condition of Environment and Natural Resource Utilization. Ministry of Energy of Kazakhstan, Astana, pp. 85-96. (in Russian) [Информацио нно-аналитический центр охраны окружающей среды (2017) Национальный доклад о состоянии окружающей среды и об использовании природных ресурсов. Министерством энергетики Республики Казахстан, Астана, pp. 85-96.]

China-Shanghai Cooperation Organization Environmental Protection Center (2018) "SCO Member States Environmental Protection Cooperation Concept” passed, member countries will strengthen multilateral and bilateral cooperation in the field of environmental protection. http://www.csecc.org.cn/ zhxx/zxyw/201806/t20180612_442986.shtml. (in Chinese 
with English versions) [中国-上海合作组织环境保护中心 （2018）《上合组织成员国环保合作构想》通过，成员国 将加强环保领域的多双边合作.] http://www.csecc.org.cn/ zhxx/zxyw/201806/t20180612_442986.shtml. (accessed on 2019-07-20)

Danqinko AM, Kabanova SA (2007) Especially protected natural territories and problems of biodiversity conservation in Kazakhstan. Boreal Coniferous Forest, (2/3), 179-182. (in Russian) [Данченко АМ, Кабанова СА (2007) Особо охраняемые природные территории Республики Казахстан и проблемы сохранения биоразнообразия. Хвойные бореальной зоны, (2/3), 179-182.]

Greenkaz (2019) Conception of Transition to Green Economy of Kazakhstan. https:/www.greenkaz.org/images/for_ news/pdf/npa/koncepciya-po-perehodu.pdf. (in Russian) [Greenkaz (2019) Концепция по переходу Республики Казахстан к «зеленой экономике». https://www.greenkaz. org/images/for_news/pdf/npa/koncepciya-po-perehodu.pdf. (accessed on 2019-05-11)

Hu RJ, Jiang FQ, Wang YJ, Li JL, Li YM, Abdimijit Ablekim, Luo GP, Zhang JM (2014) Arid ecological and geographical conditions in five countries of Central Asia. Arid Zone Research, 31, 1-12. (in Chinese with English abstract) [胡汝 䩀, 姜逢清, 王亚俊, 李均力, 李耀明, 阿布都米吉提·阿 布力克木, 罗格平, 张建明 (2014) 中亚(五国)干旱生态 地理环境特征. 干旱区研究, 31, 1-12.]

Krainiuk V, Abisheva K, Valyhanova A (2005) Thematic Review: Biodiversity. Ministry of Environmental Protection of Kazakhstan. UNDP, GEF, Astana, pp. 9-22. (in Russian) [Крайнюк В, Абишева К, Валиханова А (2005) Тематический обзор: Биологическое разнообразие. ПРООН-ГЭФ-МООС, Астана, pp. 9-22.]

Li Y, Zhou L, Kadirov TA, Shi L (2013) Bird community diversity in Khujand region of Tajikistan in summer. Journal of Xinjiang Agricultural University, 36, 472-477. (in Chinese with English abstract) [李叶, 周鹿, 卡迪诺夫TA, 时否 (2013) 塔吉克斯坦苦戞市周边地区夏季鸟类群落 多样性. 新疆农业大学学报, 36, 472-477.]

Literature Database (2016) The Redbook of Kazakhstan. https://bankreferatov.kz/ecologiya/4297-krasnaya-kniga-ka zahstana.html. (in Russian) [Банк рефератов (2016) Красная книга Казахстана. https://bankreferatov.kz/ecolo giya/4297-krasnaya-kniga-kazahstana.html.] (accessed on 2019-07-10)

Meng HH, Gao XY (2019) Global biodiversity and conservation along the Belt and Road Initiative. Bulletin of Chinese Academy of Sciences, 34, 818-824. (in Chinese with English abstract) [孟宏虎, 高晓阳 (2019) “一带一路”上的 全球生物多样性与保护. 中国科学院院刊, 34, 818-824.]

Ministry of Agriculture of Kazakhstan (2018) Sixth National Report of Biodiversity. GEF and UNDP, Аsтана. (in Russian) [MCX РК (2018) Шестой национальный доклад Республики Казахстан о биологическом разнообразии.
GEF and UNDP, Астана.]

Ministry of Energy of Kazakhstan (2015) Conception of Biodiversity Conservation and Sustainable Use in Kazakhstan to 2030. GEF and UNDP, Аsтана. (in Russian) [Министерство энергетики Республики Казахстан (2015) Концепция по сохранению и устойчивому использованию биологического разнообразия Республики Казахстан до 2030 года. GEF and UNDP, Астана.]

Ministry of Environment and Water Resources of Kazakhstan (2014) Fifth National Report of Biodiversity. Kazakhstan Biodiversity Conservation Association, Astana. (in Russian) [Министерство окружающей среды и водных ресурсов Республики Казахстан (2014) Пятый национальный доклад Республики Казахстано биологическом разнообразии. Казахстанская ассоциация сохранения биоразнообразия, Астана.]

National Ecological Information Fund (2019) International Conventions in the Field of Environmental Protection Ratified and Signed by Kazakhstan. http://ecogosfond.kz/or husskajakonvencija/dostup-k-jekologicheskoj-informacii/ha ly-araly-yntyma-tasty. (in Russian) [Государственный Фонд экологической информации (2019) Перечень Международных конвенций в области охраны окружающей среды, ратифицированных, подписанных Республикой Казахстан. http://ecogosfond.kz/orhusskajakonvencija/dostup-k-jekologicheskoj-informacii/haly-aralyyntyma-tasty.] (accessed on 2019-07-10)

Parshina GN, Mukiyanova U, Shbanova LV (2012) Biodiversity conservation and management in Kazakhstan: Issues and tasks. KazNU Bulletin: Biology Series, (2), 16-20. (in Russian) [Паршина ГН, Мукиянова У, Шабанова ЛВ (2012) Сохранение и управление биоразнообразием в Республике Казахстан: проблемы и задачи. KazNU Bulletin: Biology Series, (2), 16-20.]

Regional Ecology Centre of Central Asia (2009) Information Review on Five Ecological Issues in Kazakhstan, pp. 3-50. CARNET, Almaty. (in Russian) [Региональный экологический центр Центральной Азии (2009) Информационно-аналитический обзор по пяти экологическим вопросам Республики Казахстан, рр. 3-50. CARNET, Алматы.]

Sadvakasov AT (2012) Especially protected natural territories of Kazakhstan: Current situation and development prospects. In: Proceedings of the Symposium on Geography Education and Cartography, Kharkov, pp. 110-112. (in Russian) [Садвакасова АТ (2012) Особо охраняемые природные территории Казахстана: Современное Состояние и Перспективы Развития. Проблеми Безперервної Географічної Освіти і Картографії, Збірник Наукових Праць, Харків, pp. 110-112.]

Scientific Information Centre of the Inter-State Commission on Sustainable Development (2007) Comprehensive Assessment of the Situation of the Environment in Central 
Asia. UNEP, Ashgabat. (in Russian) [НИЦ МКУР (2007) Интегрированная оценка состояния окружающей среды ЦА. UNEP, Ашйхабад.]

UNEP (2003) Environment and Security-A Case Study of Central Asia and South-eastern Europe. Transformation of Crisis and Cooperation. UNDP and OSCE, Chatelaine, pp.10-15. (in Russian) [ЮНЕП (2003) Окружающая среда и безопасность-Примеры из Центральной Азии и Юго-Восточной Европы. Трансформация Рисков в Сотрудничество. ПРООН and ОБСЕ, Chatelaine, pp. 10-15.]

Wang LX (translator) (2019) Political economic analysis of Central Asian water security under the background of the Belt and Road Initiative. The Information Monitoring Express of Science and Technology in Central Asia, (3), 1-5. (in Chinese) [王丽贤(编译) (2019) “一带一路”倡议背 景下中亚水安全的政治经济学分析. 中亚科技信息监测 快报, (3), 1-5.]

World Bank (2019) Countries and Economies. http://data.world bank.org.cn/country. (accessed on 2019-08-10)

Wu M (translator) (2018) China’s “Belt and Road” project and the consequences of the Central Asian water crisis. The
Information Monitoring Express of Science and Technology in Central Asia, (3), 3-5. (in Chinese) [吴永(编译) (2018) 中国的 “一带一路”项目与中亚水危机的后果. 中亚科技 信息监测快报, (3), 3-5.]

Zhang XY, Wu M, Chen X, Luo GP (2010) Biological diversity in Kazakhstan and Xinjiang. Arid Land Geography, 33, 183-185. (in Chinese with English abstract) [张小云, 吴沝, 陈曦, 罗格平 (2010) 哈萨克斯坦生物多样性及其与中国 新疆的比较. 干旱区地理, 33, 183-185.]

Zhou KF, Zhang Q, Chen X (2006) The characteristics and trend of the change of ecological environment in arid areas of central Asia. Science in China (Series D), 36(A2), 133-139. (in Chinese with English abstract) [周可法, 张清, 陈曦 (2006) 中亚干旱区生态环境变化的特点和趋势. 中国科学: D辑, 36(增刊2), 133-139.]

Official Site of the President of the Republic of Kazakhstan (2019) The Strategy for Development of the Republic of Kazakhstan. http://www.akorda.kz/ru/official_documents/ strategies_and_programs. (accessed on 2019-05-11)

(责任编委: 徐靖 责任编辑: 时意专) 